\title{
Prognosis of respiratory tract infections in primary
} \section{care}

In the third paragraph of this Editorial (BMJ 2013;347:f7185, doi:10.1136/bmj.f7185), the years listed between which "the incidence of patients attending primary care for respiratory tract infections in the UK fell by $38 \%$ during summer and by $48 \%$ during winter" were wrong. These changes were observed between 1994 and 2000, not "1997 and 2009" as was published.

Cite this as: BMJ 2014;348:9290

๑ BMJ Publishing Group Ltd 2014 